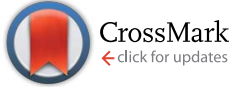

Cite this: J. Mater. Chem. A, 2015, 3 , 4846

Received 16th November 2014 Accepted 8th January 2015

DOI: $10.1039 / c 4 t a 06226 d$

www.rsc.org/MaterialsA

\section{Novel AuPd nanostructures for hydrogenation of 1,3-butadiene $\uparrow$}

\author{
Huimei Chen, ${ }^{\text {ab }}$ Jiale Huang, ${ }^{\text {ac }}$ Dengpo Huang, ${ }^{a}$ Daohua Sun, ${ }^{a}$ Minhua Shao*c \\ and Qingbiao Li ${ }^{\mathrm{abd}}$
}

Exotic AuPd bimetallic nanoflowers (NFs) are facilely synthesized using a microorganism-mediated, cetyltrimethylammonium chloride (CTAC)-directed method at room temperature. The NFs consist of one-dimensional long pedicels and three-dimensional open horns. The effect of cell dosage and feed concentrations of ascorbic acid (AA), CTAC and metal precursors on the morphology of the bimetallic nanostructures were studied. The results showed that all the obtained materials were alloys with $\mathrm{Pd}$ enriched surfaces. The diameters of the horns decreased, while those of the pedicels increased with increasing the feed concentration of $\mathrm{Pd}$ precursor. The presence of $\mathrm{Pd}$ precursor was vital for the formation of the nanowire part of the NF structure. Furthermore, the AuPd-NF/microorganism materials exhibited excellent catalytic performance and durability toward the hydrogenation of 1,3-butadiene.

\section{Introduction}

Metals have found extensive use in many diverse applications ranging from catalysis to electronics, photonics, information storage, sensing, imaging, medicine, and photography, as well as the generation, conversion, and storage of energy. ${ }^{1}$ With the development of nanotechnology, the fabrication of metal nanostructures that maximizes the surface area of metals with tunable shapes and properties has been intensively studied in the past decade., ${ }^{1,2}$ It has been thought that bimetallic nanostructures might outperform the corresponding monometallic nanostructures due to a synergetic effect in catalysis. ${ }^{2}$ At present, various methods, including co-reduction, ${ }^{2,3}$ pyrolysis, ${ }^{4}$ seed-mediated method, ${ }^{5}$ hydrothermal method, ${ }^{6}$ and galvanic replacement, ${ }^{7-9}$ have been developed for fabricating bimetallic nanostructures with various shapes.,.$^{2,3,6,7,9-14}$ However, shape control of bimetallic nanostructures based on a versatile strategy still remains challenging.

The microbial biosynthesis of metal nanoparticles has been regarded as a novel and viable alternative to chemical and

\footnotetext{
${ }^{a}$ Department of Chemical and Biochemical Engineering, College of Chemistry and Chemical Engineering, Xiamen University, Xiamen 361005, PR China. E-mail: cola@ xmu.edu.cn; kemshao@ust.hk; Fax: +86-592-2184822; Tel: +86-592-2183088

${ }^{b}$ Environmental Science Research Center, College of the Environment \& Ecology, Xiamen University, Xiamen 361005, PR China

'Department of Chemical and Biomolecular Engineering, Hong Kong University of Science and Technology, Clear Water Bay, Hong Kong, PR China

${ }^{a}$ College of Chemistry \& Life Science, Quanzhou Normal University, Quanzhou 362000, PR China

$\dagger$ Electronic supplementary information (ESI) available: The corresponding histograms of diameter distribution, SEM images, table of XPS peak positions, product conversion and selectivity in 1,3-butadiene hydrogenation, adsorption rates of Au and Pd (1:1) adsorbed by the PPCs. See DOI: 10.1039/c4ta06226d
}

physical methods for the synthesis of metal nanostructures. ${ }^{15-17}$ It was thought that metal ions could be adsorbed and reduced by the microbial surface, resulting in very small nanoclusters that would gradually grow into metal nanoparticles over the microorganisms. ${ }^{17,18}$ However, the shape of the metal nanostructures could not be effectively controlled by microorganisms alone. Inspired by the wet chemical synthesis of tunable $\mathrm{Au}$ nanorods in the presence of Au seeds $;^{19}$ herein, we tried a synthesis of microorganism-bound Au nanoparticles with very small size as seeds for the shape control of one-dimensional (1D) gold nanostructures at room temperature. Functional Aunanowire/microorganism nanocomposites could be obtained with Pichia pastoris cells (PPCs) and Escherichia coli cells (ECCs) in the presence of hexadecyltrimethylammonium bromide (CTAB).$^{\mathbf{2 0 , 2 1}}$ Interestingly, using cetyltrimethylammonium chloride (CTAC) instead of CTAB, this approach could be expanded to the synthesis of chemically difficult-to-synthesize Au nanohorns (Au NHs). ${ }^{22,23}$ Therefore, the microorganism-mediated, surfactant-directed (MSD) synthesis has been proposed as a new method for the shape control of metal nanostructures at room temperature.

It is well known that binary metal ions can be simultaneously adsorbed by microorganisms. The nanoparticles formed by the reduction of microorganism-bound binary metal ions can act as nuclei for the growth of novel bimetallic nanostructures. The advantage of the MSD approach is that bimetallic nanostructures can be obtained in one pot at room temperature. Furthermore, the problem of metal leaching that occurs in galvanic replacement reactions for synthesizing bimetallic nanostructures can be circumvented. In addition, the bimetallic nanostructures can form application-oriented nano-composites with microorganisms. In terms of these factors, herein, we 
describe a proof of concept MSD approach to synthesize novel AuPd bimetallic nanoflowers (NFs) consisting of a one-dimensional pedicel and three-dimensional horn in this study. Such NFs have not been reported hitherto, partially due to the extreme difficulty in their synthesis by a pure chemical reduction method. The as-obtained AuPd-NF/microorganism nanocomposites can be directly used as an efficient catalyst for the hydrogenation of 1,3-butadiene. This work opens a new avenue to the shape control of novel bimetallic nanostructures, and should find promising applications in catalysis.

\section{Experimental section}

\section{Materials and methods}

The same Pichia pastoris GS115 cell powder, which was used in our previous work, was employed in this work as well. Chloroauric acid $\left(\mathrm{HAuCl}_{4}\right)$, palladium chloride $\left(\mathrm{PdCl}_{2}\right)$, cetyltrimethylammonium chloride (CTAC) and ascorbic acid (AA) were all purchased from Sinopharm Chemical Reagent Co. Ltd. in China. Deionized (DI) water was used throughout this work.

\section{Preparation of AuPd bimetallic nanostructures}

Three steps were adopted in a typical synthesis of AuPd bimetallic nanostructures. First, dried PPCs (0.005 or $0.01 \mathrm{~g})$ were added to $10 \mathrm{~mL}$ of aqueous CTAC solution (1.0, 5.0, 10.0 or 15.0 $\mathrm{mM}$ ) in a flask. Subsequently, aqueous $\mathrm{HAuCl}_{4}(48.6 \mathrm{mM}$, $0.0514 \mathrm{~mL})$ and $\mathrm{H}_{2} \mathrm{PdCl}_{4}(0.05 \mathrm{M}, 0.050 \mathrm{~mL})$ solutions were added to the mixture. Finally, 0.05 , 0.1 or $0.5 \mathrm{~mL}$ AA $(0.1 \mathrm{M})$ was added to the mixture. The color of the solution turned from orange red to light orange immediately after adding the AA solution. The flask was then placed on a shaker $\left(30^{\circ} \mathrm{C}, 150 \mathrm{rpm}\right)$ for 1-24 h. A few precipitates were observed at the bottom of the flasks after $0.5 \mathrm{~h}$ of reaction while the colour of the solution turned to black. The final AuPd/PPC samples were centrifuged at $2000 \mathrm{rpm}$ for $10 \mathrm{~min}$ and dispersed in $200 \mu \mathrm{L}$ of deionized water for further characterizations. It should be noted that the aqueous $\mathrm{Au}$ and $\mathrm{Pd}$ solutions were added into the mixture via three different modes. For Mode A, Au and Pd precursors were simultaneously added into the mixture, and then a $50 \mathrm{~min}$ interaction between the cells and metal ions was allowed before the addition of AA. For Mode B, Au precursor was added after the Pd precursor reacted for $50 \mathrm{~min}$. Mode $\mathrm{C}$ was the reverse of Mode B.

\section{Characterizations of AuPd bimetallic nanostructures}

Transmission electron microscopy (TEM) characterization was performed on an electron microscope (Tecnai F30, FEI; Netherlands) with an accelerating voltage of $300 \mathrm{kV}$. Scanning electron microscopy (SEM) samples of the suspension were fabricated by dropping the suspension onto a clean silicon wafer. SEM observations were carried out on a Hitachi S-4800 SEM system. The sizes of AuPd NFs were measured on the basis of the SEM images. ${ }^{24}$ After centrifugation, the precipitates were dried at $50{ }^{\circ} \mathrm{C}$ in vacuum and used for X-ray diffraction (XRD) and X-ray photoelectron spectroscopy (XPS) analysis, which were performed on a Rigaku Ultima IV X-ray Diffractometer
(Rigaku, Japan) and a Quantum 2000 spectrometer using the Al$\mathrm{K} \alpha$ line as the excitation source, respectively. The binding energy was calibrated by $\mathrm{C}$ 1s as the reference energy (C 1s = $284.8 \mathrm{eV}$ ). Supernatant solutions were decanted after removing the composites by centrifuging to analyze the $\mathrm{Pd}(\mathrm{II})$ and $\mathrm{Au}$ (III) concentrations using atomic absorption spectrophotometry (AAS) (Pgeneral, China). The compositions of Au and Pd in the obtained sample dissolved in aqua regia were also analyzed by AAS.

\section{Hydrogenation of 1,3-butadiene}

The catalytic reactions were carried out at $35{ }^{\circ} \mathrm{C}$ in a $1 \mathrm{~cm}$ diameter fixed bed flow stainless reactor under atmospheric pressure using a feed concentration of 2.13\% 1,3-butadiene, 4.29\% $\mathrm{H}_{2}$, and $93.58 \% \mathrm{~N}_{2} \cdot{ }^{25}$ The temperature was measured using a glass tube covered $\mathrm{Cr}-\mathrm{Al}$ thermocouple located in the centre of the catalyst bed. The catalyst (15 mg of AuPd/PPC composites) was diluted with $50 \mathrm{mg}$ of quartz sand before being loaded into the reactor with a space velocity of $9230 \mathrm{~mL} \mathrm{~h}^{-1}$ $\mathrm{g}_{\text {cat. }}{ }^{-1}$. The reactor effluent was analyzed online every $20 \mathrm{~min}$ within a $2 \mathrm{~h}$ period using a gas chromatograph (GC) equipped with an $\mathrm{Al}_{2} \mathrm{O}_{3}$ column and a FID detector. The conversion of 1,3butadiene and its selectivity to butene (trans-2-butene, 1butene, or cis-2-butene) or butane were calculated.

\section{Results and discussion}

\section{Synthesis and characterizations of AuPd bimetallic nanoflowers}

Effect of metal precursors adding mode. Following our previous work on the synthesis of $\mathrm{Au} \mathrm{NHs,2,23}$ the MSD approach was expanded to bimetallic nanostructures in this work. Interestingly, as shown in Fig. 1, exotic NFs comprising one-dimensional pedicels (nanowires) and three-dimensional open nanohorns were obtained by reducing $\mathrm{HAuCl}_{4}$ and $\mathrm{H}_{2} \mathrm{PdCl}_{4}(0.25 \mathrm{mM}, \mathrm{Au} / \mathrm{Pd}$ ratio of $1: 1$, Mode A and $\mathrm{B})$ in the presence of AA (1.0 mM), PPCs $(5 \mathrm{mg})$ and CTAC $(5.0 \mathrm{mM})$. The diameters of the pedicels and horns were denoted as $d_{\mathrm{p}}$ and $d_{\mathrm{h}}$, respectively. To the best of our knowledge, similar nanostructures have not been reported hitherto. On the basis of Mode A and B, the approximate $d_{\mathrm{h}}$ of the as-synthesized NFs was ca. $0.26 \pm 0.08 \mu \mathrm{m}$ (Fig. S1 in ESI $\dagger$ ). However, the $d_{\mathrm{p}}$ of the NFs by Mode A $(31.1 \pm 6.9 \mathrm{~nm})$ was considerably larger than that by Mode B $(18.8 \pm 4.6 \mathrm{~nm})$ (Fig. $\mathrm{S} 1 \dagger)$. As revealed by EDX spectra

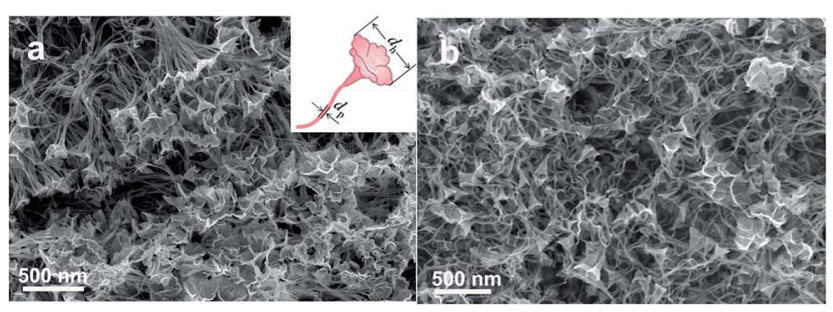

Fig. 1 SEM images of AuPd bimetallic nanostructures with a flowerlike structure synthesized through (a) Mode A and (b) Mode B. The inset in Fig. 1a indicates a model of AuPd flower-like structure. 
(Fig. S2 $\dagger$ ), the local $\mathrm{Au} / \mathrm{Pd}$ ratio of the NFs was about 1.27. The overall $\mathrm{Pd} / \mathrm{Au}$ atomic ratio was further determined to be $\mathrm{ca} .0 .80$ by AAS analysis, lower than the initial ratio of 1.0 (Fig. S3 $\%$ ). The reduction potential of $\left[\mathrm{AuCl}_{4}\right]^{-} / \mathrm{Au}\left(\left[\mathrm{AuCl}_{4}\right]^{-} / \mathrm{Au}=+1.002 \mathrm{~V}\right.$ vs. standard hydrogen electrode (SHE)) was higher than that of $\left[\mathrm{PdCl}_{4}\right]^{2-} / \mathrm{Pd}\left(\left[\mathrm{PdCl}_{4}\right]^{2-} / \mathrm{Pd}=+0.591 \mathrm{~V}\right.$ vs. SHE) $.^{26} \mathrm{Thus}, \mathrm{AuCl}_{4}{ }^{-}$ is easier to be reduced compared to $\left[\mathrm{PdCl}_{4}\right]^{2-}$. As a result, $c a$. $20 \% \mathrm{Pd}$ was left in the solution, which greatly reduced Pd leaching compared with galvanic replacement reaction. In contrast to Mode A and B, Mode $\mathrm{C}$ led to the formation of nanoparticles (NPs) $(74.7 \pm 8.8 \mathrm{~nm}$, Fig. S4†) rather than NFs. To prepare the AuPd bimetallic NFs, further characterizations and synthetic study of the NFs were based on the facile Mode A.

The AuPd NFs prepared on the basis of Mode A were further characterized by TEM, HRTEM, SAED and EDX line profiles. TEM image (Fig. 2a) indicates that the open nanohorns connected with thin pedicels to form a NF structure. HRTEM images (Fig. 2b and c) and the corresponding fast Fourier transform (FFT) pattern (insets in Fig. 2b and c) show that the corresponding blossom and pedicel are polycrystalline with well-defined lattice planes. The $d$-spacing of the blossom was about $0.230 \mathrm{~nm}$, matching the in-between value of the facecentered cubic (fcc) $\mathrm{Au}(111)$ and $\mathrm{Pd}(111)$ planes. ${ }^{12,27}$ Another $d$ spacing for the adjacent lattice fringes of the pedicel was 0.250 $\mathrm{nm}$, which corresponds to the forbidden $1 / 3\{422\} .{ }^{28}$ Moreover, the common (111) plane could be determined from the pedicel (Fig. S5 $\dagger$ ). The typical SAED pattern (Fig. 2d) from the AuPd NFs shows Bragg reflections of $\{111\},\{200\},\{220\}$ and $\{311\}$ of fcc AuPd. The EDX elemental line scanning of an individual AuPd

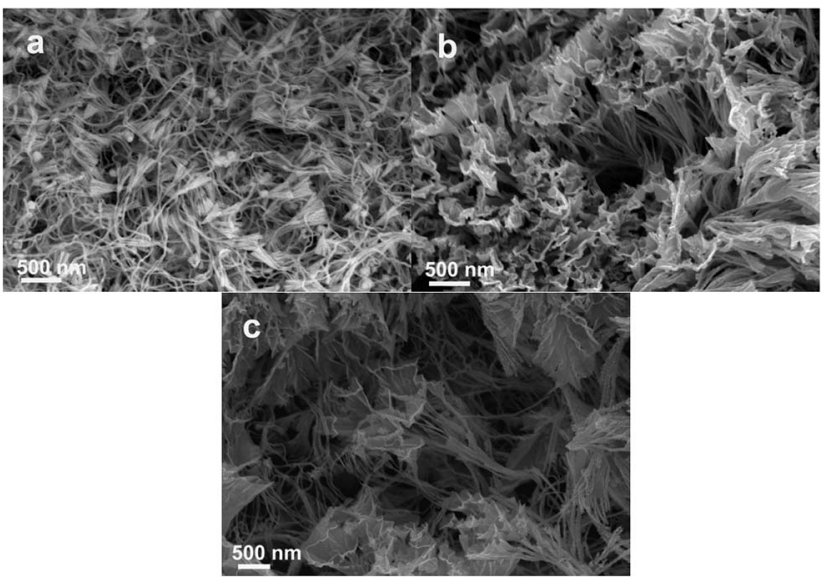

Fig. 3 SEM images of AuPd bimetallic nanostructures synthesized by Mode A with various CTAC concentrations of (a) $1.0 \mathrm{mM}$, (b) $10.0 \mathrm{mM}$ and (c) $15.0 \mathrm{mM}$. The initial concentrations of the other chemicals were $\mathrm{HAuCl}_{4}=0.25 \mathrm{mM}_{2} \mathrm{H}_{2} \mathrm{PdCl}_{4}=0.25 \mathrm{mM}$ and $\mathrm{AA}=1.0 \mathrm{mM}$, while the dosage of PPCs was $5 \mathrm{mg}$.

nanowire (pedicel) (Fig. 2e) illustrates that they were composed of $\mathrm{Au}$ and $\mathrm{Pd}$, demonstrating their bimetallic alloy nature. Subsequently, controlled experiments were further performed to study the effect of CTAC, AA and Pd concentrations, and cell dosage on the morphology of the AuPd NFs.

Effect of CTAC. Fig. 3 shows the SEM images of AuPd NFs synthesized by varying the feeding concentration of CTAC $\left(C_{\mathrm{CTAC}}\right)$, keeping the other conditions the same. By reducing the
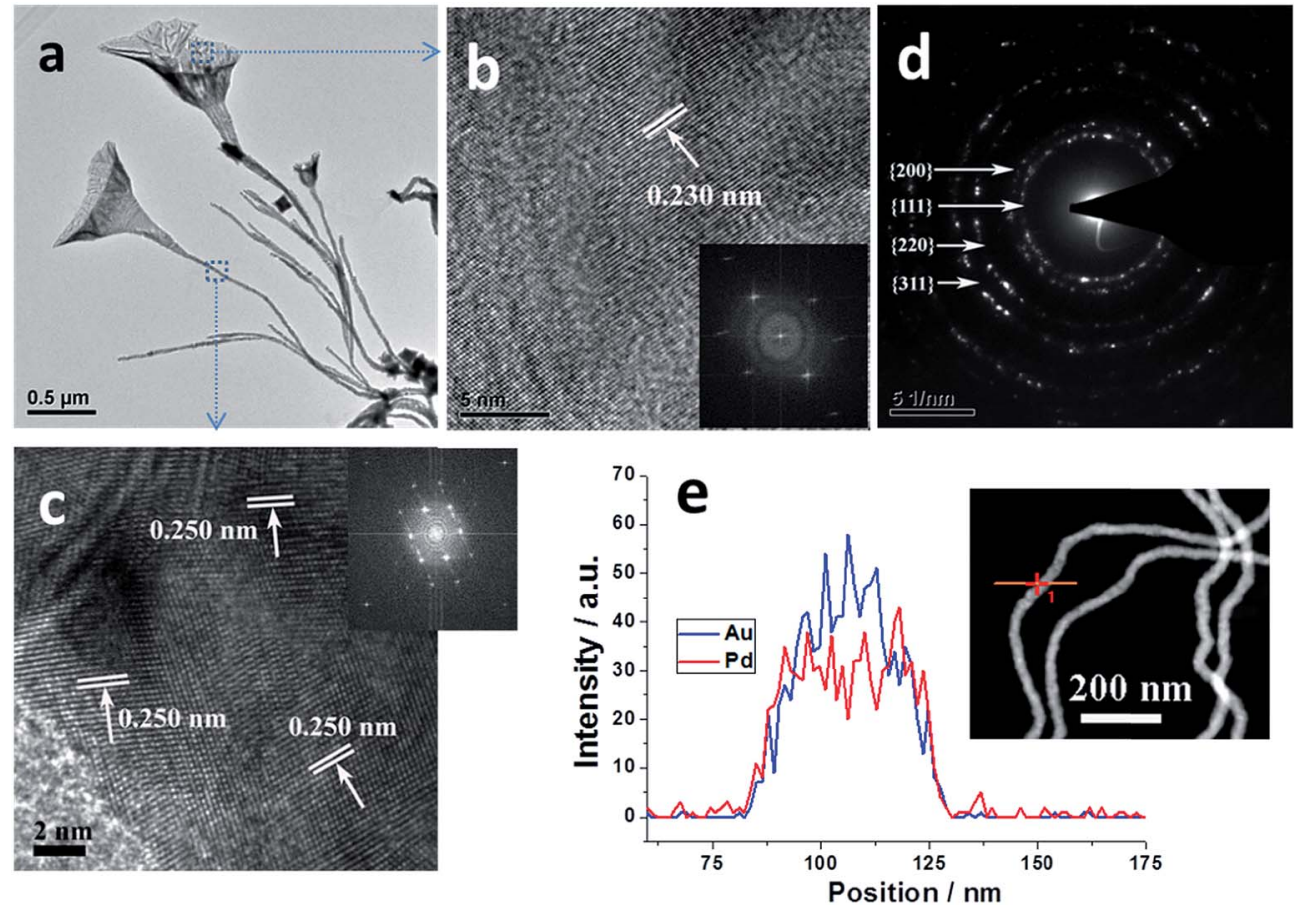

Fig. 2 (a) TEM image of AuPd NFs synthesized by Mode A, (b) HRTEM image of a blossom, (c) HRTEM image of a pedicel, (d) SAED pattern of AuPd NFs, and (e) EDX line profiles of an individual AuPd nanowire (pedicel) corresponding to the framed part (dash) in (a). The insets indicate the corresponding fast Fourier transform (FFT) pattern. 
CTAC concentration from $5.0 \mathrm{mM}$ (Fig. 1) to $1.0 \mathrm{mM}$ (Fig. 3a), long nanowires with buds at one end were obtained. The nanostructures did not change with CTAC concentration doubling from $5.0 \mathrm{mM}$ to $10.0 \mathrm{mM}$ (Fig. 3b), while the $d_{\mathrm{h}}$ slightly decreased to $0.25 \pm 0.06 \mu \mathrm{m}$ (Fig. S6a $\dagger$ ) from $0.26 \pm 0.08 \mu \mathrm{m}$. When CTAC concentration was further increased to $15.0 \mathrm{mM}$, the $d_{\mathrm{h}}$ of the NF structures became much larger $(0.51 \pm 0.2 \mu \mathrm{m}$, Fig. $3 \mathrm{c}$ and $\mathrm{S} 6 \mathrm{~b} \dagger$ ). As demonstrated in our previous reports, ${ }^{22,23}$ CTAC had a great impact on the morphology of the nanostructures. The $\mathrm{CTA}^{+}$ions released from CTAC could promote the anisotropic growth of nanostructures. When CTAC was replaced with octadecyltrimethylammonium chloride (OTAC) and dodecyltrimethylammonium chloride (DTAC) with a concentration of $5.0 \mathrm{mM}$, small NPs instead of NF structures were formed (Fig. S7 $\dagger$ ). When CTAC was replaced with CTAB, only nanowires were obtained due to the co-existence of $\mathrm{CTA}^{+}$ and $\mathrm{Br}^{-}$. Thus, CTAC was favorable for the formation of the AuPd NFs.

Effect of AA. As a mild reducing reagent, AA also had a strong effect on the morphology of AuPd nanostructures. Fig. 4a and b depict the SEM images of AuPd nanostructures prepared at the initial AA concentration $\left(C_{\mathrm{AA}}\right)$ of $0.5 \mathrm{mM}$ and $5.0 \mathrm{mM}$, respectively. Interestingly, uniform smooth nanowires without hornlike structures (Fig. 4a) were obtained by halving the AA concentration used in Fig. 1 . In addition, the $d_{\mathrm{p}}$ of the nanowires $(22.3 \pm 4.7 \mathrm{~nm}$, Fig. S8a $\dagger$ ) was smaller than that in Fig. 1a $(31.1 \pm 6.9 \mathrm{~nm})$. By increasing the AA concentration to $5 \mathrm{mM}$, the horn-like structures remained with shorter pedicels. The $d_{\mathrm{h}}$ of the nanohorns in Fig. $4 \mathrm{~b}$ was $0.29 \pm 0.14 \mu \mathrm{m}$, which is slightly larger than that in Fig. 1a (Fig. S8b $\dagger$ ). To demonstrate the distribution of $\mathrm{Pd}$ and $\mathrm{Au}$ in the nanostructures, STEM elemental mapping characterization was carried out. Fig. 5a and $\mathrm{b}$ indicate the homogeneous distribution of $\mathrm{Au}$ (green) and Pd (orange) in the NW and NF structures, respectively.

Effect of cell dosage. The effect of the cell dosage $\left(m_{\text {cell }}\right)$ on the shape of the nanostructures was also examined. Without PPCs, irregular petals and rough nanobelts were obtained (Fig. 6a). In contrast, AuPd NFs were produced in the presence of PPCs. Our previous studies showed that the biosorption of $\mathrm{Au}(\mathrm{III})$ and Pd(II) ions by the PPCs was rather rapid. ${ }^{17,18}$ Thus, $\mathrm{Au}(\mathrm{III})$ and $\mathrm{Pd}$ (II) ions can be easily bound to the cells. As a result, the binding sites act as preferential nucleation sites for the

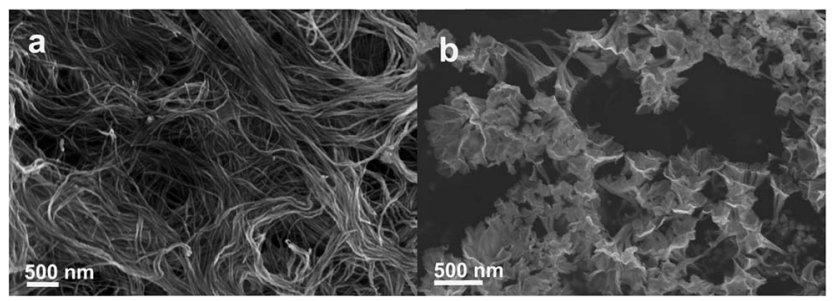

Fig. 4 SEM images of AuPd bimetallic nanostructures synthesized by Mode $A$ at the AA concentration of (a) $0.5 \mathrm{mM}$ and (b) $5.0 \mathrm{mM}$. The initial concentrations of the other chemicals were $\mathrm{HAuCl}_{4}=0.25 \mathrm{mM}$, $\mathrm{H}_{2} \mathrm{PdCl}_{4}=0.25 \mathrm{mM}$ and CTAC $=5.0 \mathrm{mM}$, while the dosage of PPCs was $5 \mathrm{mg}$.

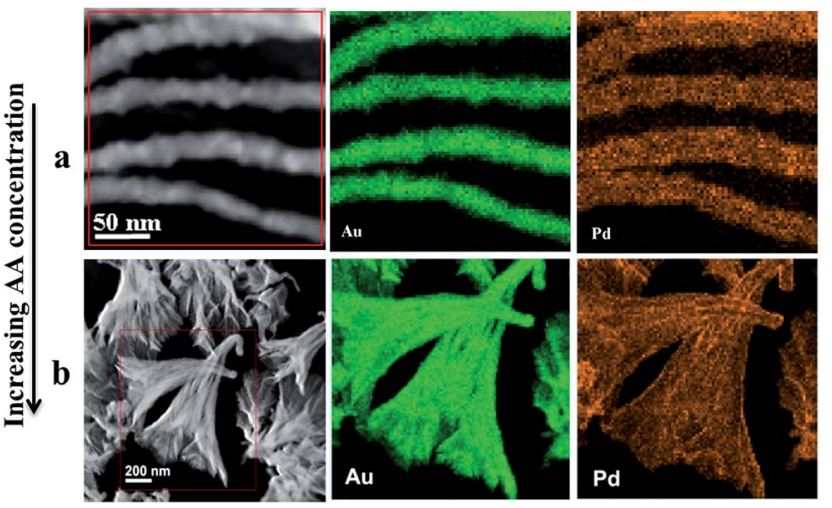

Fig. 5 AuPd bimetallic nanostructures characterized by HAADF-STEM and STEM elemental mapping (green indicates $A u$ and orange indicates $\mathrm{Pd}$ ). The nanostructures were synthesized in the presence of $A A$ with a concentration of (a) $0.5 \mathrm{mM}$ and (b) $5.0 \mathrm{mM}$. The initial concentrations of the other chemicals were $\mathrm{HAuCl}_{4}=0.25 \mathrm{mM}$, $\mathrm{H}_{2} \mathrm{PdCl}_{4}=0.25 \mathrm{mM}$ and CTAC $=5.0 \mathrm{mM}$, while the dosage of PPCs was $5 \mathrm{mg}$.

growth of AuPd NPs, which further evolve into AuPd NFs under the direction of CTAC. The effect of the PPC dosage on the morphology of the bimetallic nanostructures was further investigated. Compared with Fig. 1, when the cell dosage was doubled from $5.0 \mathrm{mg}$ to $10.0 \mathrm{mg}$, NFs with shorter and thicker pedicels (Fig. 6b) were attained. Thus, more AuPd NPs were distributed over the cell surface by increasing the number of cells. However, AuPd NPs were less concentrated over PPCs, which prevented the formation of potential AuPd NFs. Therefore, excess amounts of PPCs could form shorter and thicker pedicels rather than AuPd NFs. Therefore, the appropriate amount of PPCs should be determined in order to form welldefined AuPd NFs. The PPCs have dual functions, i.e. in the biosorption of binary metal ions and as a platform for preferential nucleation.

Effect of Pd concentration. By comparison with our previous work on Au NHs, ${ }^{22,23}$ AuPd NFs with long pedicel nanostructures were produced by introducing Pd into the system. In other words, the nanowire morphology (pedicel) was promoted. Thus, the effect of the initial $\mathrm{Pd}: \mathrm{Au}$ ratio on the morphology of nanostructures was investigated. The Pd : Au ratio of $X: 5$ ( $X=$ $1,3,5,7,9)$ was adjusted by changing the Pd precursor

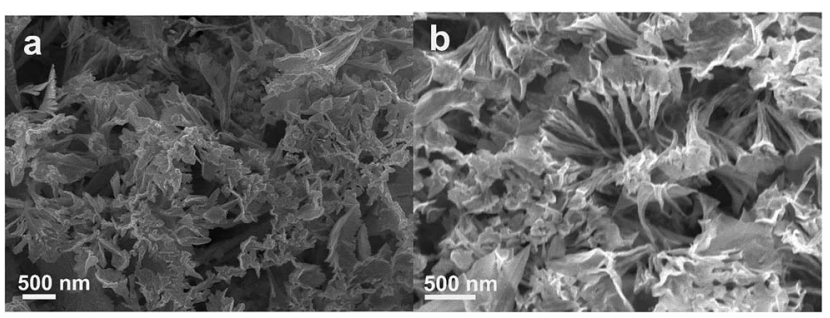

Fig. 6 SEM images of AuPd bimetallic nanostructures synthesized through Mode A in the presence of dried PPCs of (a) $0 \mathrm{~g}$ and (b) $0.01 \mathrm{~g}$. The initial concentrations of the other chemicals were $\mathrm{HAuCl}_{4}=0.25$ $\mathrm{mM}, \mathrm{H}_{2} \mathrm{PdCl}_{4}=0.25 \mathrm{mM}, \mathrm{CTAC}=5.0 \mathrm{mM}, \mathrm{AA}=1.0 \mathrm{mM}$. 


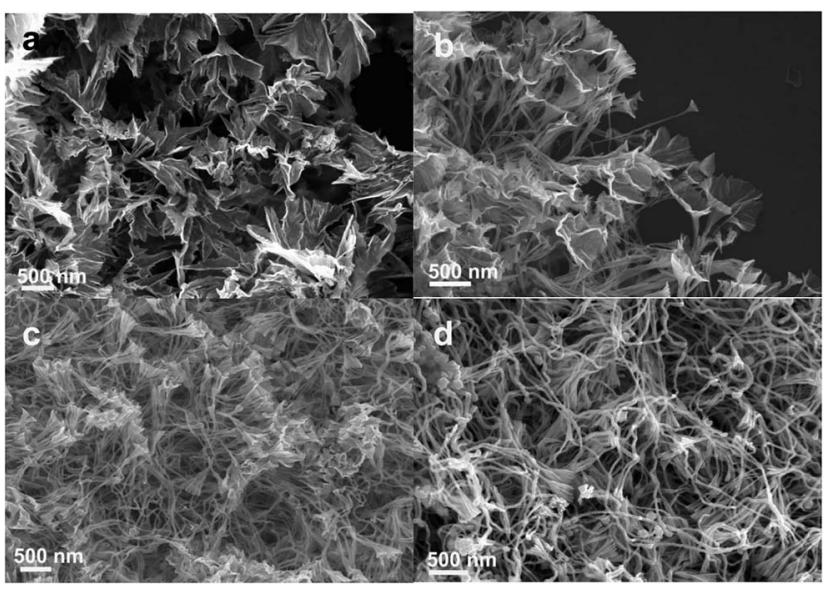

Fig. 7 SEM images of AuPd nanostructures synthesized by Mode $A$ at $\mathrm{Pd}$ : Au ratios of $X: 5$ where $X$ is (a) 1, (b) 3, (c) 7, (d) 9. The initial concentrations of the other chemicals were $\mathrm{HAuCl}_{4}=0.25 \mathrm{mM}, \mathrm{CTAC}$ $=5.0 \mathrm{mM}$ and $\mathrm{AA}=1.0 \mathrm{mM}$, while the dosage of PPCs was $5 \mathrm{mg}$.

concentration while keeping the Au precursor concentration constant. Fig. 7 shows the SEM images of AuPd nanostructures synthesized at different $\mathrm{Pd}: \mathrm{Au}$ ratios, apart from the $\mathrm{Pd}: \mathrm{Au}$ ratio of $5: 5$ for Fig. 1a. When a small amount of Pd (Pd : Au ratio $=1: 5$ ) was added, petals with rough multi-serrated-like nanobelts were obtained without pedicels (see Fig. 7a). Welldefined NFs structures with long thin pedicels were formed with increasing the $\mathrm{Pd}: \mathrm{Au}$ ratio to $3: 5$ (see Fig. $7 \mathrm{~b}$ ). The morphology in Fig. 7b was very similar to that in Fig. 1 (Pd : Au ratio $=5: 5$ ). When further increasing the Pd content, pedicel structures were still retained, while horn-like structures disappeared. Instead, nanoparticles or a two-dimensional broom at the end of wire appeared (see Fig. $7 \mathrm{c}$ and d). It was found that the diameters of the horns gradually decreased with increasing the Pd concentrations, i.e. $d_{\mathrm{h}}$ were $0.69 \pm 0.27 \mu \mathrm{m}, 0.29 \pm 0.09$ $\mu \mathrm{m}$ and $0.24 \pm 0.06 \mu \mathrm{m}$ (see Fig. S9a-c $\dagger$ ) corresponding to Fig. 7a-c, respectively. Conversely, the diameters of the nanowires increased from $27.8 \pm 7.3 \mathrm{~nm}$ to $34.8 \pm 5.5 \mathrm{~nm}$ (see Fig. S9d-f $\dagger$ ). Therefore, the formation of nanowires was attributed to Pd in this system. In the previous report, Zhu et al. also demonstrated that Pd played a crucial role in forming the nanowire morphology in the alloy nanostructure. ${ }^{9}$

To investigate the structures, valence states and elemental distributions of the prepared materials at different Pd:Au ratios, XRD, XPS and HAADF-STEM characterizations were carried out. The XRD results (see Fig. 8a) show that the diffraction peaks of different $\mathrm{Pd}: \mathrm{Au}$ ratios are located between those of pure Au (pdf2 card: 00-002-1095) and Pd (pdf2 card: 01087-0635), which can be indexed to the (111), (200) and (220) of the fcc structure of $\mathrm{Au}$ and Pd. The (111) diffraction peak exhibits a shift from pure Au to pure Pd with increasing the Pd content (see the inset of Fig. 8b). Also, a good linear relationship was found between the diffraction angles and the Pd mole fractions in Fig. 8b. According to Vegard's law, this linear relationship indicated that the prepared AuPd nanostructures were alloy and that the composition of each bimetallic nanostructure was proportional to that of the feeding solution..$^{11,12,29}$

XPS was adopted to study the valence states and surface compositions of $\mathrm{Au}$ and Pd at different Pd : Au ratios. Fig. 9a shows the XPS peaks of $\mathrm{Au}(0) 4 \mathrm{f}_{7 / 2}$ and $4 \mathrm{f}_{5 / 2}$ for the PdAu nanostructures. The binding energies shift gradually to lower energies as the Pd content increases. Interestingly, the binding energies of $\operatorname{Pd}(0) 3 \mathrm{~d}_{5 / 2}$ and $3 \mathrm{~d}_{3 / 2}$ shift gradually to higher energies with increasing Pd content, as shown in Fig. 9b. The binding energies are summarized in Table S1. $\dagger$ The slight shifts in binding energy indicated the changes in the electronic properties of both $\mathrm{Au}$ and $\mathrm{Pd}$ on/near the surface of the NF materials, further verifying the formation of the alloy nanostructures. ${ }^{27,30}$ According to the XPS results, all the AuPd alloy nanostructures have Pd-enriched surfaces (see the last column in Table S1 $\dagger$ ). That is, the Pd:Au ratios of the surfaces were much higher than the actual ratios derived from the AAS measurements. Also, the actual $\mathrm{Pd} / \mathrm{Au}$ ratio was lower than the theoretical one for each sample (see Fig. S3†). The formation of the Pd-enriched surface of the AuPd alloy nanostructures may be due to the different reduction rates of the $\mathrm{Au}$ (III) and $\mathrm{Pd}$ (II) species. Considering the reduction potential discussed above, it can be assumed that Au nuclei formed first, then followed up by adding $\mathrm{Au}$ and Pd atoms onto the nuclei, ${ }^{11}$ leading to alloy nanostructures with Pd-enriched surfaces being formed.
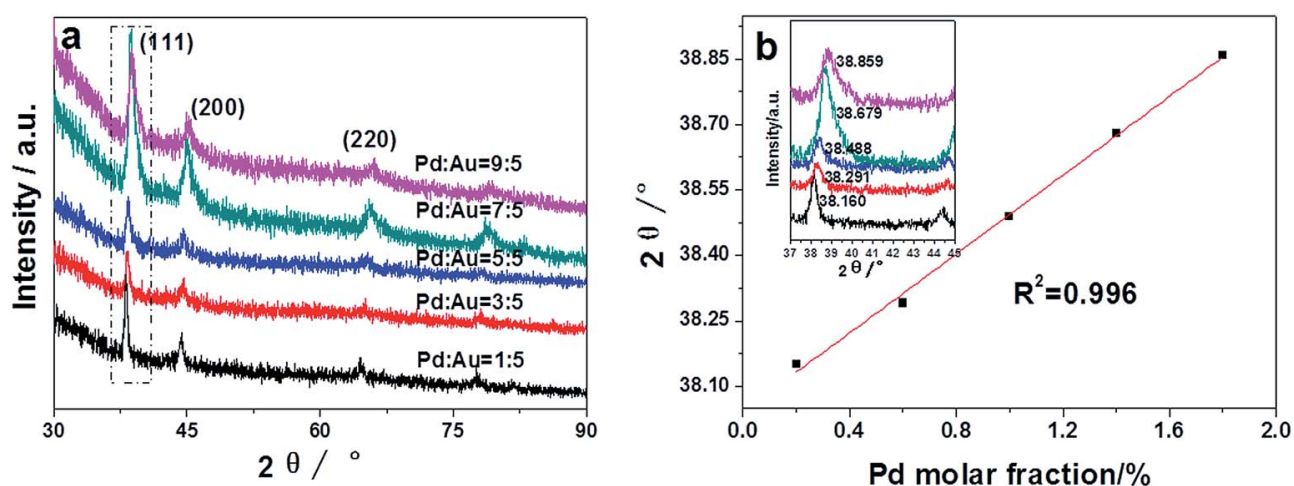

Fig. 8 (a) XRD patterns and (b) (111) diffraction peak positions of the AuPd bimetallic nanostructures with different initial AuPd molar ratios. The inset in Fig. 8b shows the XRD patterns in Fig. 8a (rectangle dashed line). 

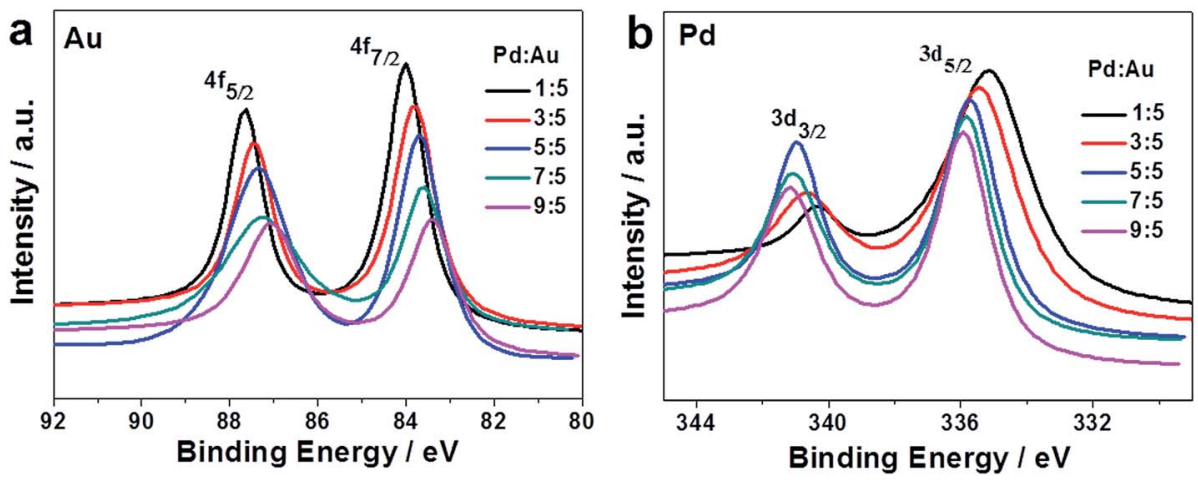

Fig. 9 XPS patterns of (a) Au $4 f$ and (b) Pd 3d of the AuPd alloy nanostructures with different initial AuPd molar ratios.

Fig. 10 shows STEM and STEM elemental mapping of AuPd alloy nanostructures at five $\mathrm{Pd}: \mathrm{Au}$ ratios, which provide insights into both the morphology and distribution of $\mathrm{Au}$ and Pd with increasing Pd concentration. From left to right, shown in Fig. 10a-e are images of the nanostructures with increasing Pd content. From up to down, each colour picture represents the elemental mappings of one nanostructure. It can clearly be seen that, the elements $\mathrm{Au}$ (green) and $\mathrm{Pd}$ (orange) are uniformly dispersed in the nanostructures. Furthermore, the morphologies are consistent with the SEM results in Fig. 1a and 7.

Formation mechanism of AuPd NFs. As discussed above, the AuPd NFs were synthesized based on Mode A and Mode B instead of Mode C (i.e. the PPCs interacted with Au(III) ions for $50 \mathrm{~min}$ prior to addition of Pd precursor). The pronounced difference showed that the Pd ions should occupy some binding sites over the cell surface, as the Au(III) ions are more easily reduced than the $\mathrm{Pd}(\mathrm{II})$ ions. When $\mathrm{Au}$ precursor was added prior to the Pd precursor, the $\mathrm{Au}(\mathrm{III})$ ions rapidly adsorbed on the cell surface. As a result, only a limited amount of binding sites on the cell surface were available for $\operatorname{Pd}(\mathrm{II})$ ions. The preferential nucleation sites on the cell surface would be predominantly occupied by $\mathrm{Au}$ nuclei, posing a difficulty for adding Pd atoms onto the sites. For Mode B, the Pd(II) ions occupied many binding sites, while fewer sites were left for the $\mathrm{Au}(\mathrm{III})$ ions, still leading to the same NF structures. Under these circumstances, tandem reactions played an important role in promoting the NF nanostructures. The first reaction was the reduction of $\operatorname{Pd}(\mathrm{II})$ ions to $\operatorname{Pd}(0)$ by AA. Then, the resulting $\operatorname{Pd}(0)$ acted as reductants for the reduction of $\mathrm{Au}(\mathrm{I})$ (even $\mathrm{Au}(\mathrm{III})$ ) ions

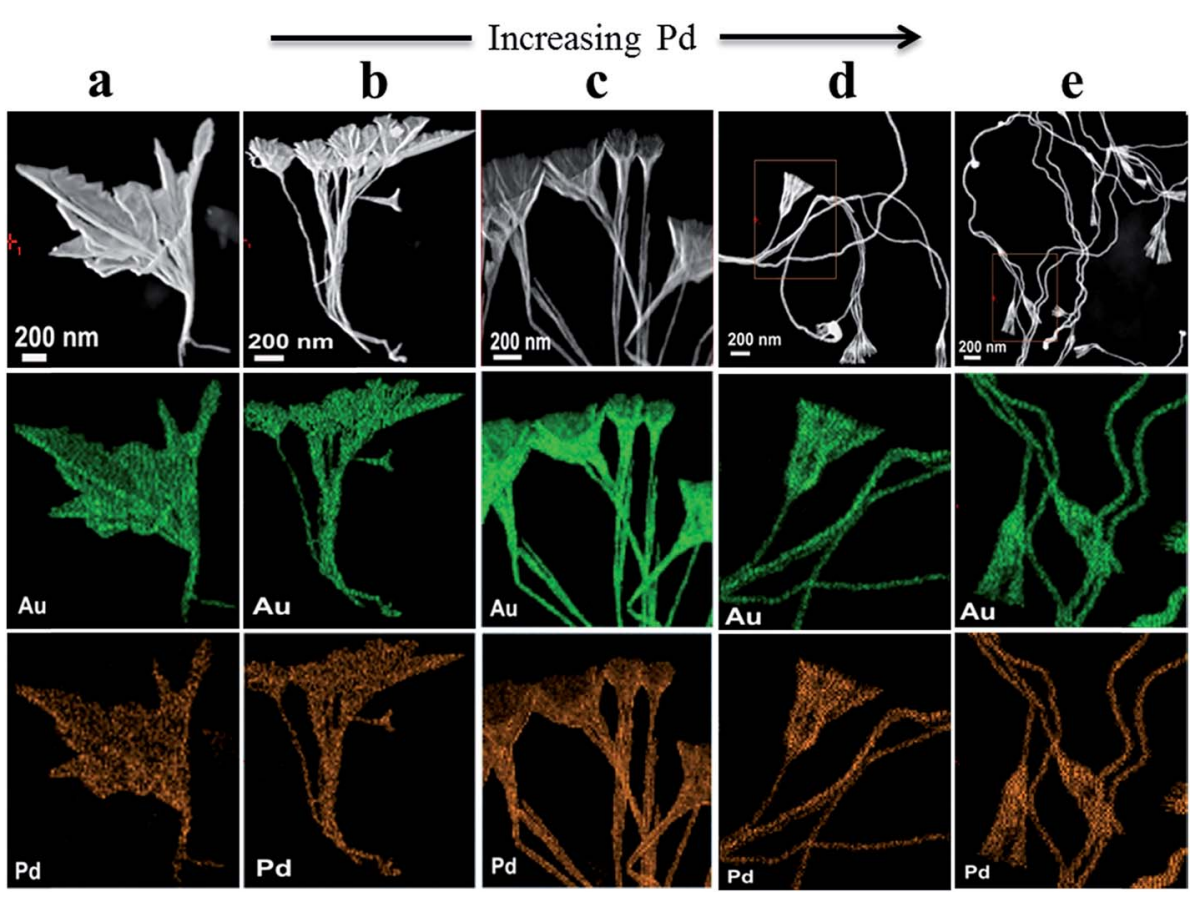

Fig. 10 From top to bottom, AuPd bimetallic nanostructures characterized by STEM and STEM elemental mapping (green indicates Au and orange indicates Pd); from left to right, AuPd bimetallic nanostructures synthesized with Pd: Au ratios of $X: 5$ where $X$ is (a) 1 , (b) 3, (c) 5, (d) 7 and (e) 9 . 

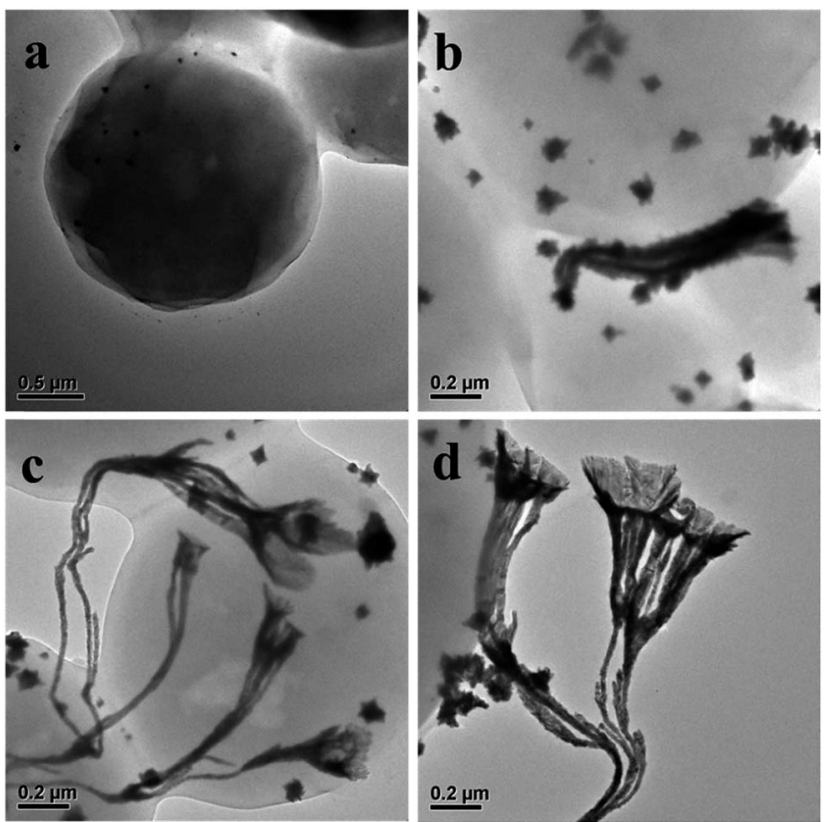

Fig. 11 AuPd nanostructures evolution at different times after the addition of AA: (a) $0 \mathrm{~min}$, (b) $5 \mathrm{~min}$, (c) $15 \mathrm{~min}$ and (d) $30 \mathrm{~min}$. The synthesis condition was the same as in Fig. 1a.

to $\mathrm{Au}(0)$ via galvanic replacement. Therefore, we tentatively believe that the tandem reactions were favourable to the addition of $\mathrm{Au}$ atoms onto the nanostructures, even when the nucleation sites were not sufficient for the Au(III) ions, as in the case of Mode B.

Through careful time-resolved TEM studies, the probable growth mechanism of AuPd NFs on the basis of Mode A was studied. When $\mathrm{HAuCl}_{4}$ and $\mathrm{PdCl}_{2}$ were added in the CTAC and PPCs solution, the colour of the solution exhibited an orange red colour at the beginning due to the presence of ligandsubstituted anions such as $\left[\mathrm{AuCl}_{4}\right]^{-},\left[\mathrm{PdCl}_{4}\right]^{2-}, \mathrm{CTA}^{+}-\mathrm{Au}(\mathrm{III})$ or $\left[\mathrm{PdCl}_{4}(\mathrm{CTA})_{2}\right]$ complexes. ${ }^{31-33}$ Next, Pd(II) and Au(III) ions were both adsorbed on the cell surface. Fifty minutes of adsorption gave rise to a balanced adsorption rate of $\mathrm{Pd}(\mathrm{II})$ and $\mathrm{Au}(\mathrm{III})$ of $c a$. $66 \%$ and $37 \%$, respectively (see Fig. S10 $\dagger$ ). In the meantime, PPCs and CTAC could act as mild reduction agents, ${ }^{17,34}$ leading to the colour change from orange red to orange, due to the reduction of $\mathrm{Au}(\mathrm{III})$ to $\mathrm{Au}(\mathrm{I})$. The $\mathrm{Au}(\mathrm{I})$ anions and $\mathrm{Au}(\mathrm{I})-\mathrm{CTAC}$ complex were colourless, ${ }^{22}$ resulting in the lighter colour of the reaction solution. Upon the addition of $\mathrm{AA}$, the colour of the solution changed to light orange immediately. As shown in Fig. 11a, there are some observable NPs on the cell surface before the addition of AA. It should be noted that CTAC was a very weak reductant at room temperature. Therefore, the NPS largely resulted from the reduction of metal ions with the cells. ${ }^{17,18}$ The nucleation of AuPd NPs grew quickly and nanowires (pedicels) appeared on the cell surfaces 5 min after the addition of AA. The nanowires preferred to grow at the junction of the two cells (see Fig. 11b). During this period, the colour of the solution changed from light pink to dark black, indicating that most of the Au ions were firstly reduced by PPCs and CTAC, while most of Pd ions were reduced by AA. EDX data showed that both NPs and nanowires contained both $\mathrm{Au}$ and Pd elements, and that the percentage Au was higher than that of Pd. The $\mathrm{CTA}^{+}$was expected to adsorb onto the crystal nucleus and thus promote the anisotropic growth of nanostructures. After $15 \mathrm{~min}$, the three-dimensional horn stretched on the cell surface and the pedicels became longer (see Fig. 11c) owing to the platforms of the PPCs for large-size nanostructures. It was noted that some AuPd NPs tended to adhere to the structures, and these NPs would be consumed via an Ostwald ripening mechanism later on during the formation of the AuPd NFs. With further growth, larger-size AuPd NFs were formed (see Fig. 11d). Eventually, after $\sim 1$ hour, most of the nanostructures evolved into well-defined AuPd NFs (see Fig. 1a) through anisotropic growth with the assistance of CTAC and the Ostwald ripening of small AuPd NPs.

Based on the TEM images, we proposed schematic illustrations for the formation of AuPd NFs, as shown in Fig. 12. First, the interaction of the PPCs with $\mathrm{Au}(\mathrm{III})$ and Pd(II) ions for over 50 minutes led to a balanced adsorption of $\mathrm{Au}$ and Pd ions onto the PPCs (at Stage I), and some Au(III) were reduced to Au(I). Next, the addition of surplus AA resulted in a further reduction of the adsorbed $\mathrm{Au}(\mathrm{I})$ and $\mathrm{Pd}(\mathrm{II})$ to form AuPd nuclei, which acted as preferential nucleation sites for the formation of AuPd NPs on PPCs (at Stage II). Then, under the direction of CTAC, the anisotropic growth of AuPd NWs with bud-like structures at the end of wires was preferred (at Stage III). Finally, well-defined AuPd NFs were formed via an Ostwald ripening during the aging of the AuPd NFs (at Stage IV).

Catalytic activity of the hydrogenation of 1,3-butadiene. The AuPd-NF/microorganism composites were explored as catalysts for the selective hydrogenation of 1,3-butadiene. The catalytic performances of the AuPd-NF/microorganism catalysts with different $\mathrm{Au} / \mathrm{Pd}$ ratios were evaluated. The previous $\mathrm{Au}-\mathrm{NW} / \mathrm{PPC}$ composites synthesized by the microorganism-mediated, ${ }^{\mathbf{2 0}}$ CTAB-directed method were also tested for comparison. Furthermore, Pd-NP/PPC composites by the microorganismmediated, CTAC-directed method (Pd NWs could not be prepared yet) was also evaluated for this reaction. It can be seen

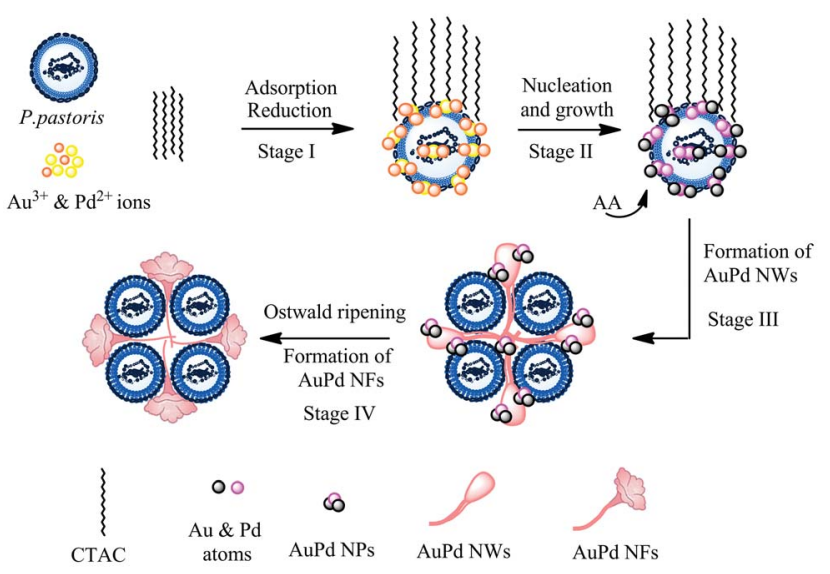

Fig. 12 Schematic diagram of the formation of AuPd NFs through the reduction of aqueous $\mathrm{HAuCl}_{4}$ and $\mathrm{PdCl}_{2}$ with $\mathrm{AA}$ in the presence of PPCs and CTAC. 

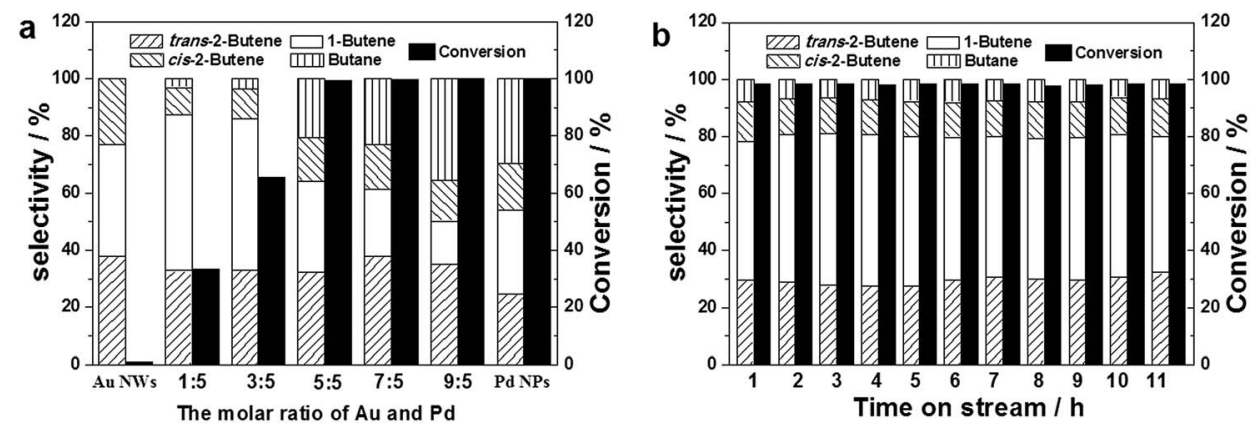

Fig. 13 (a) Catalytic performance of the AuPd-NF/microorganism catalysts and (b) the durability of AuPd (1:1) NF/microorganism catalysts in 1,3-butadiene hydrogenation.

from Fig. 13a that the Au-NW/PPC composites were inactive for the reaction with very low conversion efficiency. As far as the PdNP/PPC composites were concerned, they exhibited a high selectivity to butene (trans-2-butene, 1-butene and cis-2-butene). For the AuPd-NF/microorganism catalysts, with increasing Pd content, the conversion efficiency increased gradually from $33.2 \%$ to $100 \%$, and the selectivity to butene also improved significantly compared with the single Au-NW/PPC and Pd-NP/ PPC catalysts. As reported in the literature for the hydrogenation of 1,3-butadiene, ${ }^{35,36}$ the selectivity to butene could be enhanced by the addition of a second metal or metal oxide. It is worth pointing out that, for the AuPd-NF/microorganism catalyst (with a $\mathrm{Au} / \mathrm{Pd}$ ratio of $5: 3$ ), the selectivity to total butene and single 1-butene could reach $96.5 \%$ and $50 \%$, respectively, though the per-pass conversion efficiency was only $65.4 \%$. However, by further increasing the Pd: Au ratio to $5: 5,7: 5$ and $9: 5$, the conversion efficiency could reach $100 \%$, and the selectivity to butene was slightly lower. The difference in the selectivity and conversion efficiency can be attributed to the shift of the Pd 3d binding energy of the NFs at different Pd : Au ratios (see Fig. 9b). Therefore, the catalytic performance was composition-dependent. Also, the electron density of Pd affected the catalytic performances. ${ }^{37,38}$ By optimizing the reaction conditions, the selectivity and conversion significantly improved, up to $92.6 \%$ and $98.4 \%$, respectively (see Fig. S11†). Additionally, the stability of the AuPd NF catalysts was also evaluated and no loss in conversion or selectivity was observed within a time-on-stream of $11 \mathrm{~h}$ (see Fig. 13b). Therefore, the AuPd alloy NFs also possess the desired durability, in addition to excellent catalytic performance.

\section{Conclusions}

In summary, a simple microorganism-mediated, surfactantdirected (MSD) approach was developed to prepare the exotic and closely packed AuPd alloy nanoflowers with compositiondependent catalytic activity for 1,3-butadiene hydrogenation. The alloy structures were further confirmed by HAADF-STEM, EDX, XRD and XPS techniques. The shape of the AuPd alloy nanostructures was influenced by the cell dosages and AA and CTAC concentrations. In particular, CTAC and AA played critical roles in the morphology control. Moreover, the diameters of the pedicels increased, while those of the nanohorns decreased with increasing Pd content. In addition, the Pd element contributed to the formation of the nanowire morphology in the NF structures, and the obtained AuPd/microorganism materials possessed Pd-enriched surfaces. Importantly, the obtained AuPd NFs/microorganism materials exhibited excellent catalytic activity and durability for the hydrogenation of 1,3-butadiene.

\section{Acknowledgements}

This work was supported by the NSFC projects (no. 21106117 and 21036004). J. H. is grateful to the Fujian Provincial Administration of Civil Service for the Fujian-Hong Kong joint postdoctoral fellowship. M.S. was supported by a startup fund from the Hong Kong University of Science and Technology.

\section{Notes and references}

1 Y. N. Xia, X. H. Xia, Y. Wang and S. F. Xie, MRS Bull., 2013, 38, 335-344.

2 B. H. Wu and N. F. Zheng, Nano Today, 2013, 8, 168-197.

3 D. S. Wang and Y. D. Li, Adv. Mater., 2011, 23, 1044-1060.

4 D. H. Sun, V. Mazumder, O. Metin and S. H. Sun, ACS Nano, 2011, 5, 6458-6464.

5 Y. Ding, F. R. Fan, Z. Q. Tian and Z. L. Wang, J. Am. Chem. Soc., 2010, 132, 12480-12486.

6 X. Q. Huang, H. H. Zhang, C. Y. Guo, Z. Y. Zhou and N. F. Zheng, Nanocubes, Angew. Chem., Int. Ed., 2009, 48, 4808-4812.

7 J. Y. Chen, B. Wiley, J. Mclellan, Y. J. Xiong, Z.-Y. Li and Y. N. Xia, Nano Lett., 2005, 5, 2058-2062.

8 X. W. Teng, Q. Wang, P. Liu, W. Q. Han, A. I. Frenkel, W. Wen, N. Marinkovic, J. C. Hanson and J. A. Rodriguez, J. Am. Chem. Soc., 2008, 130, 1093-1101.

9 C. Z. Zhu, S. J. Guo and S. J. Dong, Adv. Mater., 2012, 24, 2326-2331.

10 C. R. Ghosh and S. Paria, Chem. Rev., 2012, 112, 2373-2433. 11 Y. W. Lee, N. H. Kim, K. Y. Lee, K. Kwon, M. Kim and S. W. Han, J. Phys. Chem. C, 2008, 112, 6717-6722.

12 Y. W. Lee, M. Kim, Y. Kim, S. W. Kang, J.-H. Lee and S. W. Han, J. Phys. Chem. C, 2010, 114, 7689-7693. 
13 X. Q. Huang, Y. J. Li, Y. Chen, H. L. Zhou, X. F. Duan and Y. Huang, Angew. Chem., Int. Ed., 2013, 125, 6179-6183.

14 S. E. Hunyadi and C. J. Murphy, J. Mater. Chem., 2006, 16, 3929-3935.

15 D. T. Tran, I. P. Jones, J. A. Preece, R. L. Johnston, K. Deplanche and L. E. Macaskie, Nanotechnology, 2012, 23, 055701.

16 H. M. Chen, D. H. Sun, X. L. Jing, F. F. Lu, T. Odoom-Wubah, Y. M. Zheng, J. L. Huang and Q. B. Li, RSC Adv., 2013, 3, 15389-15395.

17 L. Q. Lin, W. W. Wu, J. L. Huang, D. H. Sun, N. M. Waithera, Y. Zhou, H. T. Wang and Q. B. Li, Chem. Eng. J., 2013, 225, 857-864.

18 H. M. Chen, D. P. Huang, L. Q. Lin, T. Odoom-Wubah, J. L. Huang, D. H. Sun and Q. B. Li, J. Colloid Interface Sci., 2014, 433, 204-210.

19 N. R. Jana, L. Gearheart and C. J. Murphy, J. Phys. Chem. B, 2001, 105, 4065-4067.

20 M. Wang, T. Kong, X. L. Jing, Y. K. Hung, D. H. Sun, L. Q. Lin, Y. M. Zheng, J. L. Huang and Q. B. Li, Ind. Eng. Chem. Res., 2012, 51, 16651-16659.

21 H. X. Yang, M. M. Du, T. Odoom-Wubah, J. Wang, D. H. Sun, J. L. Huang and Q. B. Li, J. Chem. Technol. Biotechnol., 2014, 89, 1410-1418.

22 M. Wang, T. Odoom-Wubah, H. M. Chen, X. L. Jing, T. Kong, D. H. Sun, J. L. Huang and Q. B. Li, Nanoscale, 2013, 5, 65996606.

23 X. L. Jing, D. P. Huang, H. M. Chen, T. Odoom-Wubah, D. H. Sun, J. L. Huang and Q. B. Li, J. Chem. Technol. Biotechnol., 2014, 90, DOI: 10.1002/Jctb.4353.
24 M. M. Du, G. W. Zhan, X. Yang, H. X. Wang, W. S. Lin, Y. Zhou, J. Zhu, L. Lin, J. L. Huang, D. H. Sun, et al., J. Catal., 2011, 283, 192-201.

25 F. Lu, D. Sun, J. Huang, M. Du, F. Yang, H. Chen, Y. Hong and Q. Li, ACS Sustainable Chem. Eng., 2014, 2, 1212-1218.

26 Y. W. Lee, M. Kim, S. W. Kang and S. W. Han, Angew. Chem., Int. Ed., 2011, 123, 3528-3532.

27 J. Chai, F. H. Li, Y. Hu, Q. X. Zhang, D. X. Han and L. Niu, J. Mater. Chem., 2011, 21, 17922-17929.

28 M. Yamamoto, Y. Kashiwagi, T. Sakata, H. Mori and M. Nakamoto, Chem. Mater., 2005, 17, 5391-5393.

29 D. H. Sun, G. L. Zhang, X. D. Jiang, J. L. Huang, X. L. Jing, Y. M. Zheng, J. He and Q. B. Li, J. Mater. Chem. A, 2014, 2, 1767-1773.

30 M. L. Wu, D. H. Chen and T. C. Huang, Langmuir, 2001, 17, 3877-3883.

31 K. Torigoe and K. Esumi, Langmuir, 1992, 8, 59-63.

32 Z. Khan, T. Singh, J. I. Hussain and A. A. Hashmi, Colloids Surf., B, 2013, 104, 11-17.

33 J. W. Zhang, L. Zhang, S. F. Xie, Q. Kuang, X. G. Han, Z. X. Xie and L. S. Zheng, Chem.-Eur. J., 2011, 17, 9915-9919.

34 Y. W. Lee, M. Kim, Z. H. Kim and S. W. Han, J. Am. Chem. Soc., 2009, 131, 17036-17037.

35 J. Goetz, M. Volpe, C. Gigola and R. Touroude, J. Catal., 2001, 199, 338-345.

36 A. Sarkany, Z. Zsoldos, G. Stefler, J. Hightower and L. Guczi, J. Catal., 1995, 157, 179-189.

37 A. L. Dantas Ramos, P. D. S. Alves, D. A. Aranda and M. Schmal, Appl. Catal., A, 2004, 277, 71-81.

38 J. C. Bertolini, P. Delichere, B. C. Khanra, J. Massardier, C. Noupa and B. Tardy, Catal. Lett., 1990, 6, 215-223. 